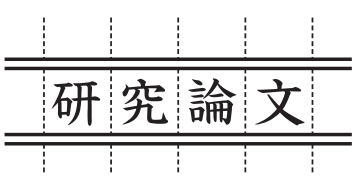

\title{
Mechanical Properties of Aluminum-Based Dissimilar Alloy Joints by Power Beams, Arc and FSW Processes
}

Michinori OKUBO*, Tomokuni $\mathrm{KON}^{* *}$ and Nobuyuki $\mathrm{ABE}^{* * *}$

(Received December 6, 2006)

\begin{abstract}
Dissimilar smart joints are useful. In this research, welded quality of dissimilar aluminum alloys of $3 \mathrm{~mm}$ thickness by various welding processes and process parameters have been investigated by hardness and tensile tests, and observation of imperfection and microstructure. Base metals used in this study are A1050-H24, A2017-T3, A5083-O, A6061-T6 and A7075-T651. Welding processes used are YAG laser beam, electron beam, metal inert gas arc, tungsten inert gas arc and friction stir welding. The properties of weld zones are affected by welding processes, welding parameters and combination of base metals. Properties of high strength aluminum alloy joints are improved by friction stir welding.
\end{abstract}

Key Words: aluminum alloy, mechanical properties, welding process, dissimilar joints, process parameters, LBW, EBW, MIG, TIG, FSWt

\section{Introduction}

The aluminum-based dissimilar alloy joints such as different alloy joints can enhance design flexibility for light weight parts and structures. Fundamental research on joints of aluminum with other metals is reported by Miller ${ }^{1}$. According to the report, a number of fusion methods are available for joining aluminum to other metals. The welding of dissimilar aluminum alloys for TIG welding was investigated by Luijendijk ${ }^{2}$. One of the authors was reported ${ }^{3,4,5)}$ concerning electron beam welding for high strength aluminum alloys. We are recommended that dissimilar aluminum alloys joints are investigated for power beams, arc and friction stir welding (FSW) processes. Dissimilar aluminum joints can be thought to be useful for the use expansion of aluminum alloys.

The present work focuses on mechanical properties of five selected processes such as YAG laser beam welding (LBW) by the optical energy, electron beam welding (EBW) by the electronic energy and MIG, TIG welding by the arc energy and FSW. The thickness of all the base metals used is $3 \mathrm{~mm}$.

In this paper, a study was carried out to clarify the properties of dissimilar alloy joints in terms of hardness, tensile and microstructure of joints by various joining processes. The optional welding conditions to be proper based on the characteristics of each welding process were discussed. The present study has observed the welded bead and evaluated hardness and tensile properties of joints.

\section{Experimental Method}

\subsection{Materials and welding equipments}

Wrought aluminum alloys used in this research are A1050-H24 pure aluminum, A2017-T3 Al-Cu alloy, A5083-O Al-Mg alloy and 6061-T6 Al-Mg-Si alloy and A7075-T651 Al-Zn-Mg alloy.

Table 1 shows the chemical compositions of the base metals.

Fig. 1 shows welding procedures for LBW, EBW, MIG and

Table 1 Chemical composition of base metals.

\begin{tabular}{|c|c|c|c|c|c|c|c|c|c|}
\hline \multirow{2}{*}{ Materials } & \multicolumn{9}{|c|}{ Elements(mass\%) } \\
\cline { 2 - 26 } & $\mathrm{Si}$ & $\mathrm{Fe}$ & $\mathrm{Cu}$ & $\mathrm{Mn}$ & $\mathrm{Mg}$ & $\mathrm{Cr}$ & $\mathrm{Zn}$ & $\mathrm{Ti}$ & $\mathrm{Al}$ \\
\hline A1050-H24 & 0.10 & 0.29 & 0.01 & - & - & - & 0.02 & bal. \\
\hline A2017-T3 & 0.59 & 0.26 & 3.87 & 0.72 & 0.57 & 0.01 & 0.02 & 0.03 & bal. \\
\hline A5083-O & 0.15 & 0.21 & 0.01 & 0.71 & 4.70 & 0.12 & 0.01 & 0.02 & bal. \\
\hline A6061-T6 & 0.57 & 0.40 & 0.27 & 0.03 & 0.96 & 0.24 & 0.02 & 0.03 & bal. \\
\hline A7075-T651 & 0.06 & 0.12 & 1.51 & 0.03 & 2.62 & 0.20 & 5.80 & 0.03 & bal. \\
\hline
\end{tabular}

* College of Industrial Technology, Nihon University (1-2-1 Izumi, Narashino-city, Chiba 275-8575 Japan)

* * Graduate School, Nihon University (1-2-1 Izumi, Narashino-city, Chiba 275-8575 Japan)

** * Smart Processing Research Center, Joining and Welding Research Institute, Osaka University (11-1 Mihogaoka, Ibaraki, Osaka 567-0047 Japan) 


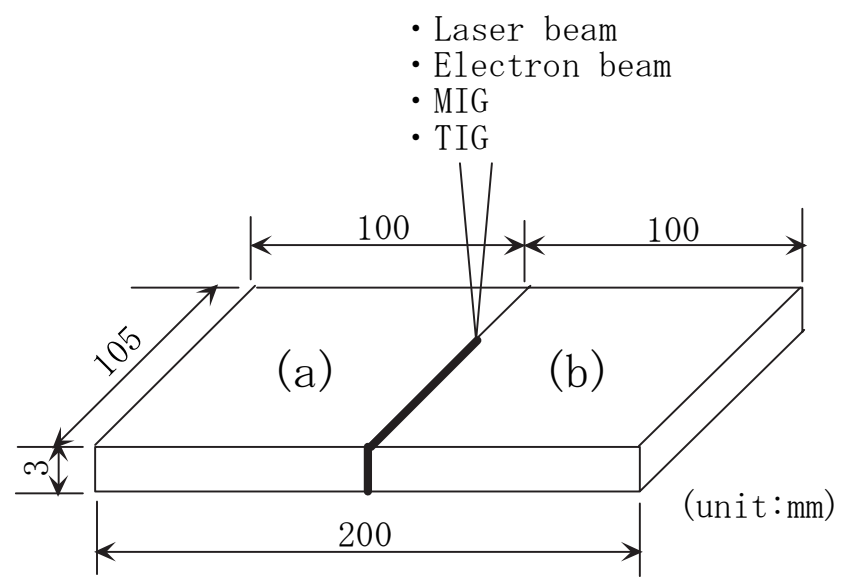

Fig. 1 Welding procedure for LBW, EBW, MIG and TIG.

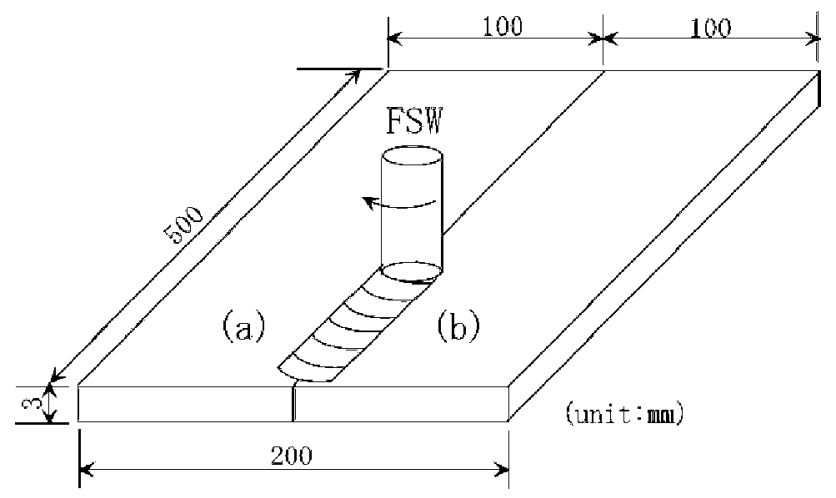

Fig. 2 Welding procedure for FSW.

TIG. The LD-YAG (CW) laser welding machine has a maximum output power of $6 \mathrm{~kW}$. The EBW machine used has the highest output power of $15 \mathrm{~kW}$. The MIG welding machine has inverter welding equipment with a maximum output of 500A. The TIG welding machine has alternating current welding equipment with a maximum output of $350 \mathrm{~A}$.

Fig. 2 shows a welding procedure for FSW. The FSW machine has a rotating tool which travels along the weld line. Base metals are fixed on the backing plate.

\subsection{Selection of process condition}

LBW was performed with an output of $3.5 \mathrm{~kW}$ and a welding speed of $3.3 \times 10^{-2} \mathrm{~m} / \mathrm{s}$. EBW was performed with an accelerating voltage of $120 \mathrm{kV}$, and a welding speed of $1.7 \times 10^{-2} \mathrm{~m} / \mathrm{s}$. The atmosphere for EBW is $5.0 \times 10^{-2} \mathrm{~Pa}$. MIG welding was performed with a welding current of $130 \mathrm{~A}$ and filler wire used was A5356-WY of $1.6 \mathrm{~mm}$ in diameter. TIG welding was performed with a welding current of 100A. In case of TIG welding, no filler material was used in order to evaluate a melting behavior.

\begin{tabular}{|c|c|}
\hline A 1050 & \\
\hline A 6061 & 100 \\
\hline A 2017 & \multirow{2}{*}{ 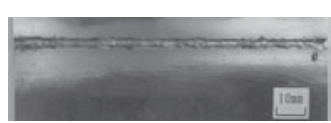 } \\
\hline A5 083 & \\
\hline A 2017 & \multirow{2}{*}{$\begin{array}{c}100 \\
100\end{array}$} \\
\hline A 7075 & \\
\hline A 5083 & \multirow{2}{*}{ 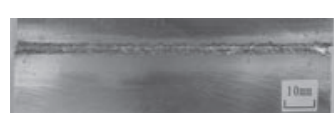 } \\
\hline A 6061 & \\
\hline A 5083 & \multirow{2}{*}{ 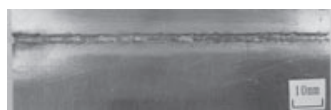 } \\
\hline A 7075 & \\
\hline
\end{tabular}

Fig. 3 Bead appearances of dissimilar alloy joints for LBW.

Optimum FSW condition was selected for each dissimilar alloy joint, but the joining speed was kept constant as $6.7 \times 10^{-3} \mathrm{~m} / \mathrm{s}$.

\subsection{Evaluation of welded joints}

Appearance of the cross section of welded joints was observed by an optical microscope. Micro Vickers hardness test was performed on the cross section. Tensile test was carried out by utilizing an Instron-type testing machine with a cross-head speed of $1 \mathrm{~mm} / \mathrm{min}$. Gage length of the tensile specimen is $50 \mathrm{~mm}$ and the cross sectional size of $3 \mathrm{~mm}$ in thickness and $25 \mathrm{~mm}$ in width.

\section{Results and Discussion}

\subsection{Observation of weld bead and bead width}

Good bead appearance, full penetration are obtained under the process condition that heat affected zone became narrow. Fig. 3 shows bead appearances of dissimilar alloy joints for LBW. Power beam energy is suitable for the welding of aluminum alloys due to its high quality ${ }^{6}$. In particular, laser welding is a promising welding method because it doesn't need vacuum chamber.

The bead widths of joints by LBW are in the range from 4.0 from $2.5 \mathrm{~mm}$. The bead widths of joints by EBW are from 1.0 to $3.5 \mathrm{~mm}$, which became narrower than those by LBW. The bead width is about $12 \mathrm{~mm}$ for the case of TIG and MIG welding. FSW showed $14 \mathrm{~mm}$ of bead width.

\subsection{Hardness distribution of joints}

Hardness in the weld zone exerts a great influence on the properties and weldability of dissimilar joints. A1050 and A5083 aluminum alloys are not aged-hardening alloys, while 
age-hardening phenomena takes place in A2017, A6061 and A7075 aluminum alloys. The hardness distribution in the weld zone of A1050/A6061aluminum alloy joint under various welding processes is shown in Fig. 4. Highest hardness was observed at weld center of joints made by FSW.

The hardness distributions in the weld zone of A2017/A5083 aluminum alloy made by various welding processes are shown in Fig. 5. In case of EBW, hardness distribution shows the highest level among all the processes, since hardness is strongly influenced by aging behavior in which the highest cooling rate is realized by EBW.

The hardness distribution in the weld zone of A2017/A7075 aluminum alloy joints with various welding processes is shown

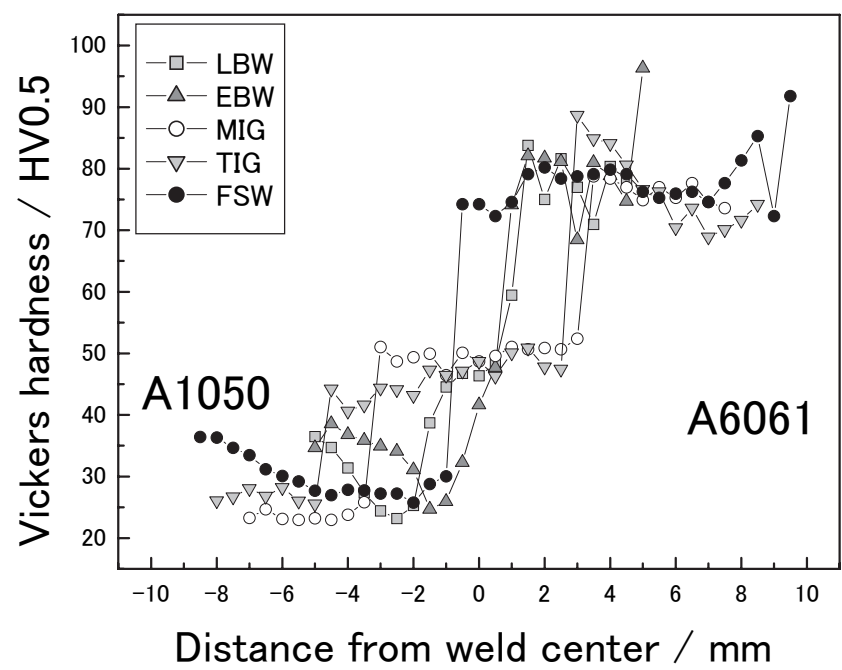

Fig. 4 Vickers hardness distribution of weld zones in A1050/A6061 alloy joint.

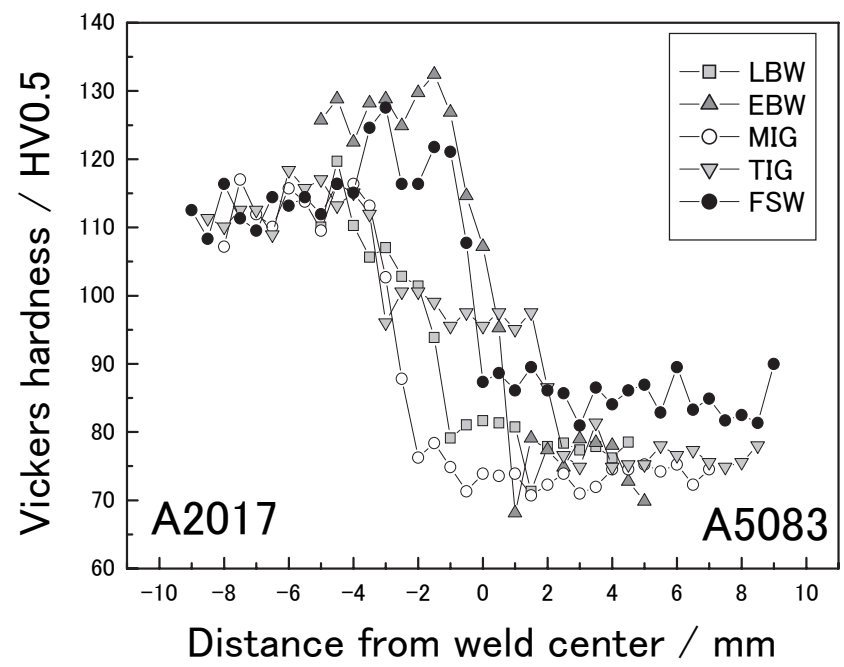

Fig. 5 Vickers hardness distribution of weld zones in A2017/A5083 alloy joint. in Fig. 6. The weld metal zone made by MIG welding shows the hardness level of around $75 \mathrm{HV}$, which is the lowest among all the welding processes performed in the present study. This is because that the MIG welding used a filler wire called A5356-WY and so the hardness of weld metal was diluted with this low hardness material.

The hardness distributions in the A5083/A6061 aluminum alloy joints made by the various welding processes are shown in Fig. 7. The hardness distribution in stir zone was almost the same level as that of base metal. There the combination of A5083 and A6061 aluminum alloys are preferable for realizing the most reliable joint.

The hardness distribution in the A5083/A7075 aluminum alloy

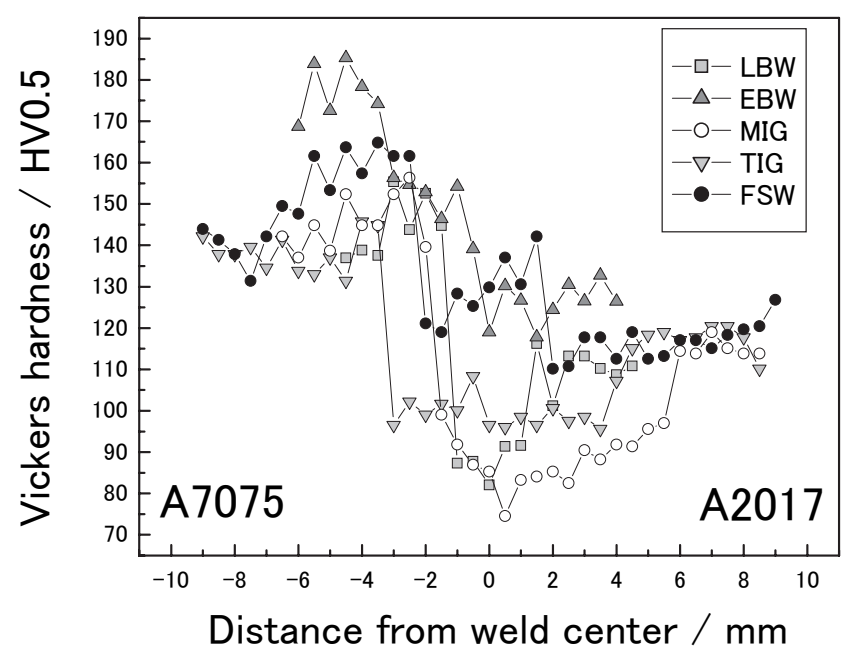

Fig. 6 Vickers hardness distribution of weld zones in A2017/A7075 alloy joint.

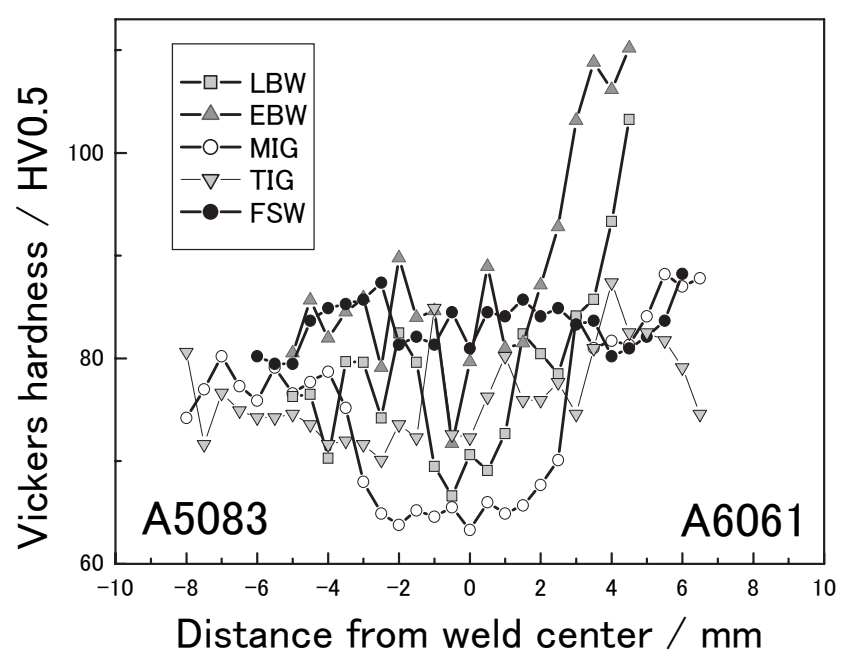

Fig. 7 Vickers hardness distribution of weld zones in A5083/A6061 alloy joint. 


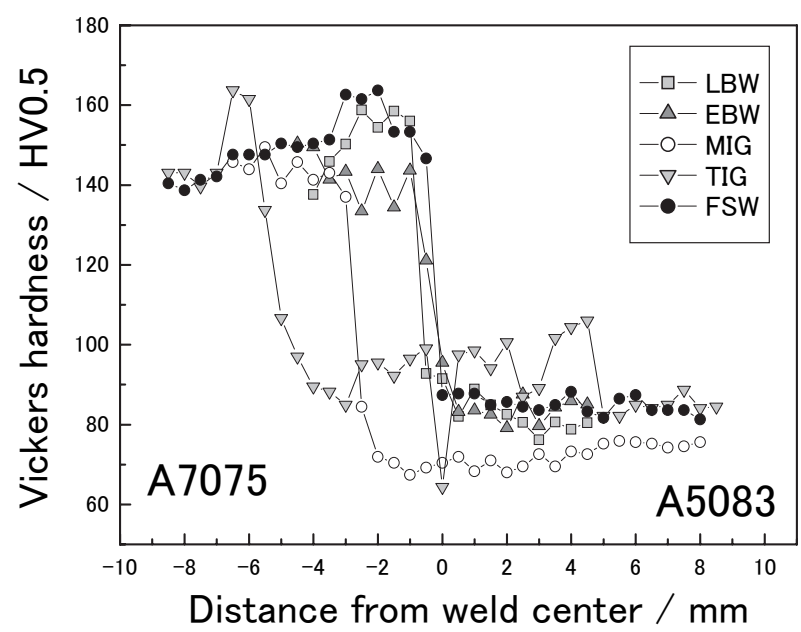

Fig. 8 Vickers hardness distribution of weld zones in A5083/A7075 alloy joint.

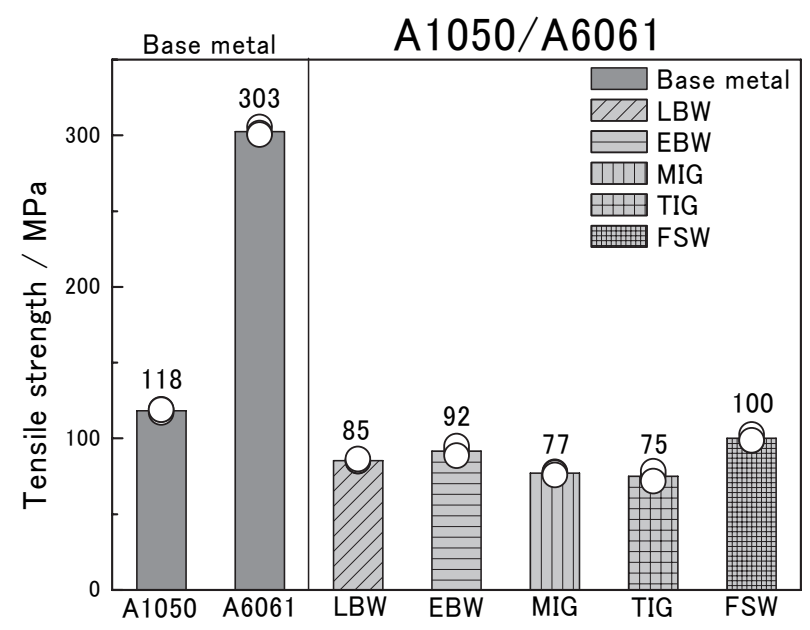

Fig. 9 Tensile strength of base metal and weld zones in A1050/A6061 alloy joint.

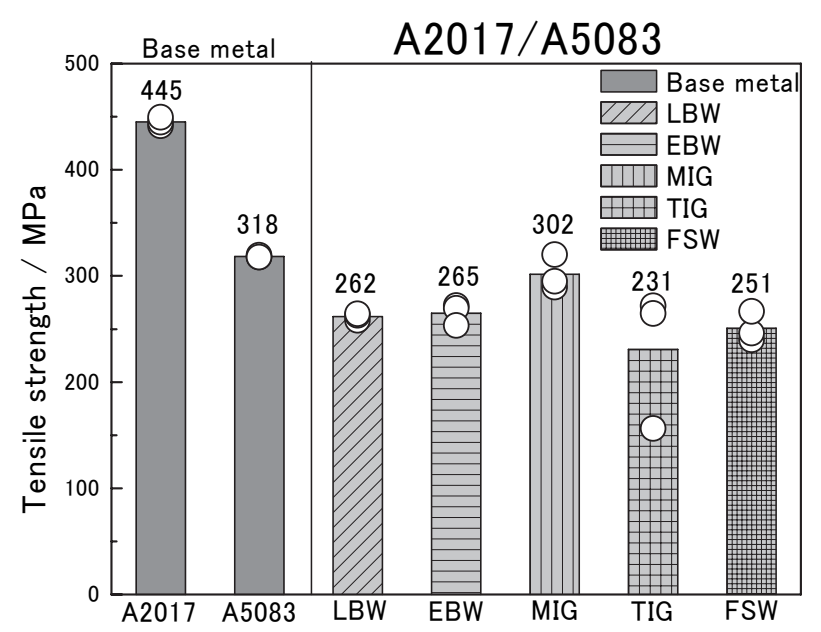

Fig. 10 Tensile strength of base metal and weld zones in A2017/A5083 alloy joint. joints by the various welding processes are shown in Fig. 8. Quite different hardness level was observed for both sides. The reasons are attributed to the difference in the chemical compositions and the age hardening behavior of base metals.

\subsection{Tensile properties of welded joints}

FSW is one of the suitable process as compared with the other conventional fusion welding processes for joining aluminum alloys ${ }^{7)}$. Since FSW is one of solid state joining process. Ericsson ${ }^{8)}$ reported that fatigue strength of friction stir welded $\mathrm{Al}-\mathrm{Mg}-\mathrm{Si}$ alloy joint is higher than the joints made by MIG-pulse and TIG welding processes, which is very useful for designing light welded constructions.

Tensile strength of A1050 pure aluminum, A2017, A5083, A6061 and A7075 aluminum alloys are $118 \mathrm{MPa}, 445 \mathrm{MPa}, 318$ $\mathrm{MPa}, 303 \mathrm{MPa}$ and $590 \mathrm{MPa}$, respectively.

Tensile strength values of the A1050/A6061 aluminum alloy joints with various welding processes are shown in Fig. 9. The joint by FSW showed the highest tensile strength than the other fusion welding methods, and the fracture occurred almost in the heat affected zone on the A1050 aluminum side.

The tensile strength values of A2017/A5083 aluminum alloy joints with various welding processes are shown in Fig. 10. MIG welding shows the highest joint efficiency of $95 \%$ against A5083 aluminum alloy, suggesting that the filler wire used for A5356-WY type was optimum.

As for the A2017/A7075 aluminum alloy joint, the results of tensile test is summarized in Fig. 11, indicating that tensile strength of the FSW joint showed the highest value among the joints tested. Thus, FSW is suitable joining method for heat-treatable alloy such as A2017 and A7075 aluminum alloys.

The result of tensile strength for A5083/A6061 aluminum alloy

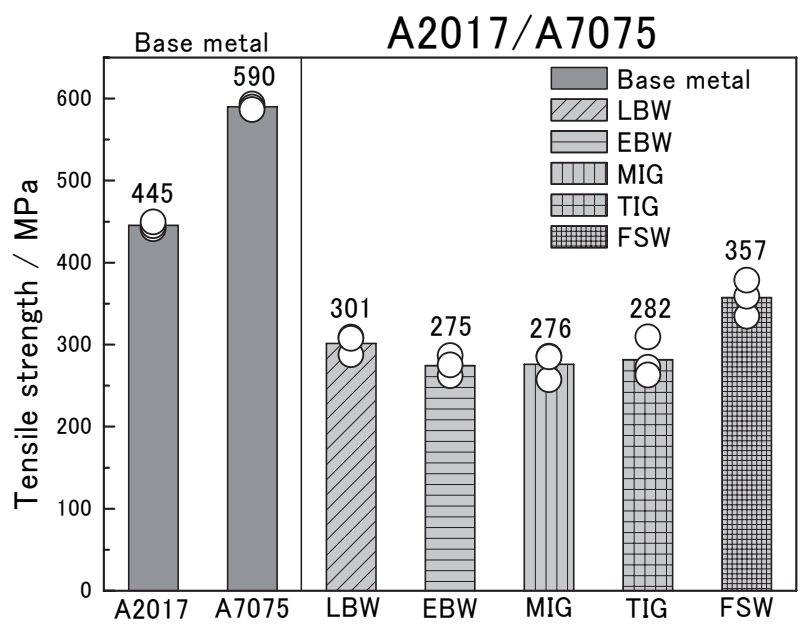

Fig. 11 Tensile strength of base metal and weld zones in A2017/A7075 alloy joint. 


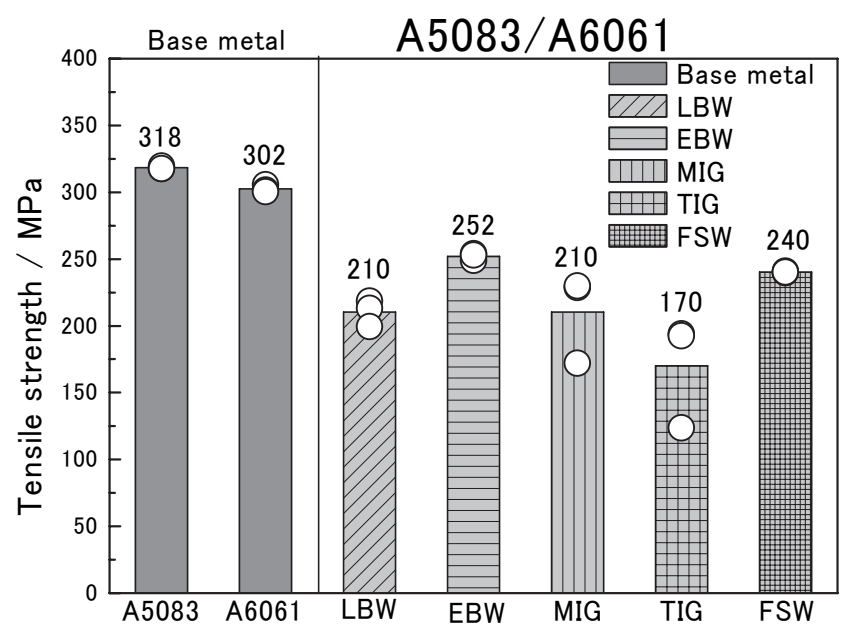

Fig. 12 Tensile strength of base metal and weld zones in A5083/A6061 alloy joint.

joints with various welding processes is shown in Fig. 12. The highest tensile strength in the A5083/A6061 aluminum alloy joint of $252 \mathrm{MPa}$ was achieved by means of EBW. Compared with base metal of A6061 aluminum alloy, the FSW joint showed a joint efficiency of about $83 \%$, which is comparable to the average tensile strength of $240 \mathrm{MPa}$ for the joint by MIG, and is slightly higher than that by TIG or other welding process.

Tensile strength of A5083/A7075 aluminum alloy joints by the various welding processes is shown in Fig. 13. The joint by MIG welding shows the highest value of $280 \mathrm{MPa}$.

\subsection{Microstructure of weld zones}

In case of power processes such as LBW and EBW, dendrite arm spacing is known to be very narrow. In this study, dendrite arm spacing of fusion zones are about $15.2 \mu \mathrm{m}$ for LBW and about $8.6 \mu \mathrm{m}$ for EBW. Fig. 14 shows a typical microstructure of SZ in an A5083/A6061 aluminum alloy joint by FSW. In this case, solid state welding reflects the metal flow of A5083 and A6061 aluminum alloys with different chemical composition. In this Figure, left side corresponds to A5083 alloy composition and right side is A6061 alloy composition. A border between un-mixed of each alloy region is featured. Metal flows in the FSW were investigated by Ouyang ${ }^{9)}$, Colligan ${ }^{10)}$ and Reynolds ${ }^{11)}$ etc. In these reports, the degrees of material mixing are affected by complex factors.

\section{Conclusions}

The present research evaluated the joints of different aluminum alloys by various welding processes in which the principle is different in terms of heat source. From this research, selection of joining process and combination of base metals are discussed.

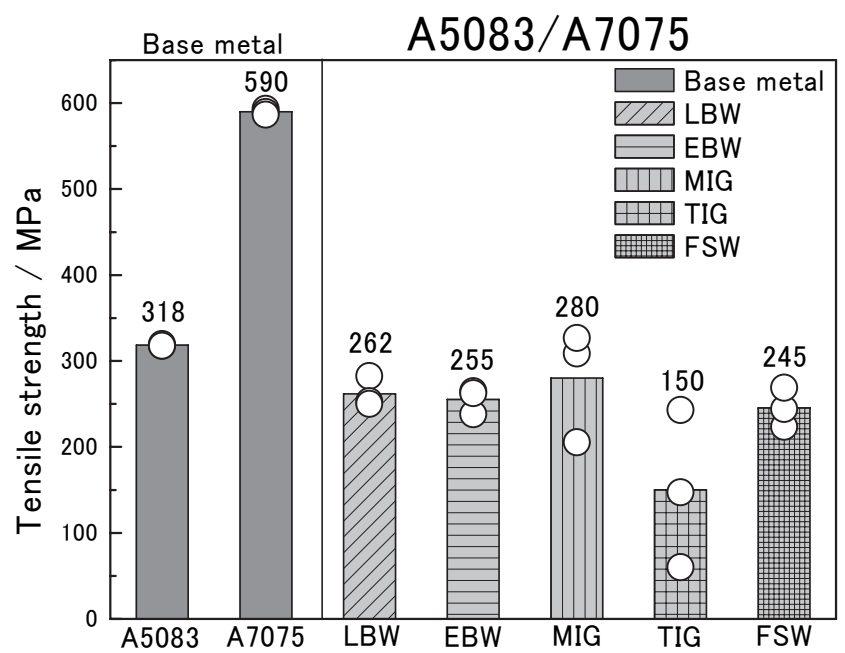

Fig. 13 Tensile strength of base metal and weld zones in A5083/A7075 alloy joint.

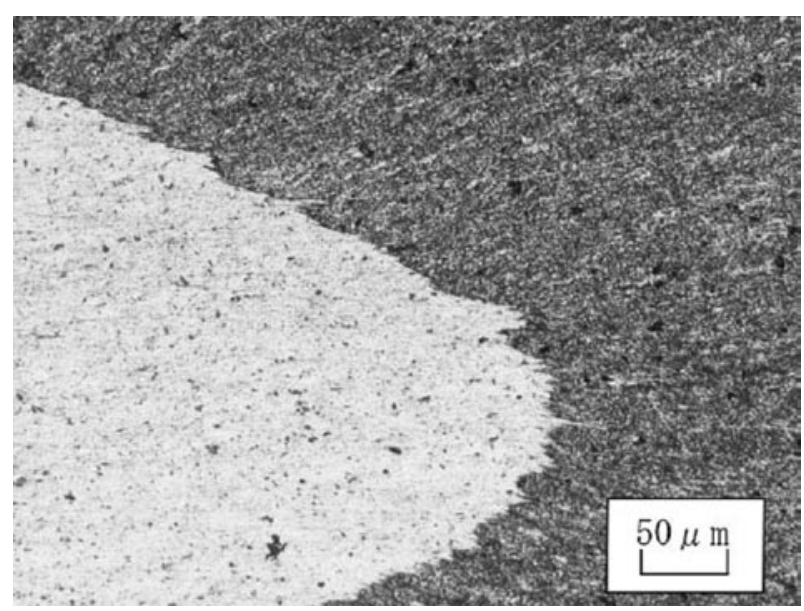

Fig. 14 Microstructure of A5083/A6061 alloy joint by FSW.

The following results are obtained.

(1) A5083/A6061 aluminum alloy joint by FSW showed the highest hardness value in stir zone though the weld metal as compared with the other fusion welding processes that showed a tendency of becoming softer than base metals.

(2) FSW was the most effective way to obtain the highest tensile strength of A2017/A7075 age-hardening aluminum alloy joint. LBW yielded a similar tensile strength in comparison with the other fusion welding processes.

(3) In power beam welding such as EBW and LBW processes, fusion and solidification zones are very narrow. Thus, the heat input is in low level compared to MIG and TIG welding processes. Typical stir zone by FSW shows a border between two un-mixed dissimilar compositions of base metals. 


\section{References}

1) Mike A. Miller: Welding Journal, 32-8(1953), 730-740.

2) T. Luijendijk: Journal of Material Technology, 103-1(2000) 29-34.

3) M. Okubo and H. Uryu: Journal of Light Metal Welding and Construction, 33-9(1995)415-423. (In Japanese)

4) H. Uryu, M. Okubo, J. Kaneko and S. Ando: Journal of Light Metal Welding and Construction,33-7(1995)303-309. (In Japanese)

5) M.Okubo: Journal of Light Metal Welding and Construction,42-8(20 04)387-391. (In Japanese)

6) T. Shida, M. Hirokawa and S. Sato: Quarterly Journal of Japan
Welding Society, 15-1(1997), 18-23.

7) W. B. Lee, Y. M. Yeon and S. B. Jung: Material Science and Technology, 19-11(2003), 1513-1518.

8) M. Ericson and R.S. Sandstrom: International Journal of Fatigue, 25(2003), 1379-1387.

9) J.H. Ouyang and R. Kovaceviv: Journal of Material Engineering and Performance, 11-1(2002), 51-63.

10) K. Colligan: Welding Journal, 75-7(1999), 229-s-237-s.

11) A. P. Reynolds: Science and Technology of Welding and Joining, 5-2(2000)120-124. 